\title{
O imaginário da imitação em Toritama
}

\section{RESUMO}

Esse artigo aborda uma das dimensões da moda, a imitação. Enquanto fenômeno socializante, a moda estabelece relações entre as pessoas, através de códigos vestimentares que "formalizam" as diversas tribos urbanas. No que concerne as tribos do agreste pernambucano, podemos perceber atualmente, na região, o imaginário destes grupos sociais cristalizado nos códigos vestimentares da produção de vestuário em jeans no município de Toritama em Pernambuco.

\section{PALAVRAS-CHAVE}

Imitação

Estética

Imaginário

\section{ABSTRACT}

This article approaches one of the dimensions of fashion, imitation. Like socializing phenomenon, the fashion establishes relationships between people through dress codes that "formalize" the various urban tribes. Regarding the tribes of the agreste of Pernambuco, it is possible to perceivetoday inthe region that the imaginary of these social groups is crystallized in the dressing codes of the production ofdenimapparelin the city of ToritamaPernambuco.

\section{KEYWORDS}

Imitation

Aesthetics

Imaginary

\section{Mario de Carvalho}

Professor do Núcleo de Design no Centro Acadêmico do Agreste da UFPE/PE/BR.

artederiva@hotmail.com

\section{José Pirquá}

Professor do Núcleo de Design no Centro Acadêmico do Agreste da UFPE/PE/BR.

jose.pirava@gmail.com 
A produção de jeans em Toritama tem sido estudada na maioria das vezes atravésde números e estatísticas. Pretendemos neste trabalho realizar uma abordagem sensível, fenomenológica, procurando encontrar as particularidades estéticas da produção em jeans e relacioná-las não só com a cultura da região, como também com o design de moda. Explora-se, portanto, dados culturais e emoções vinculadas aos artefatos em análise.

O trabalho de campo realizado para a pesquisa sobre o vestuário em jeans, no município de Toritama, nos permitiu considerar que a imitação é uma das principais características na produção deste vestuário. Esse posicionamento partiu não só de observações sobre o objeto de estudo, como também foi pautado por algumas referências teóricas como, por exemplo, as obras de Georg Simmel, Gabriel de Tarde, Jean Piaget e Michel Maffesoli.

A partir das reflexões decorrentes das observações realizadas em Toritama e do referencial teórico, consideramos aqui, a relação entre moda, imitação e imaginário.

\section{A moda e seu papel social}

A moda se caracteriza particularmente pelas diversas transformações socioeconômicas e culturais. Desde a invenção da alta-costura na França do século XIX, a questão dos gostos vestimentares apresenta-se como uma das dimensões da socialização organizada em volta de marcas e de criadores. Esta invenção coincide com a emergência da indústria de confecções, que abrange uma clientela cada vez mais vasta da sociedade. A moda caracteriza-se por sua rápida transformação e interfere igualmente no processo de identificação e transformação de uma sociedade. Devido a estas identificações, a diferenciação social na moda é atenuada no vestuário através da expansão das confecções, do prêt-à-porter, e da rápida divulgação das tendências.

\section{A moda caracteriza-se por sua rápida transformação e interfere igualmente no processo de identificação e transformação de uma sociedade.}

De uma maneira paradoxal, ao mesmo tempo em que o mundo da moda depende das oscilações do mercado, ele gera fortes influências econômicas, sociais, políticas, culturais, etc., pro- porcionando uma busca interminável e constante pelo novo. A modainterfere, desta maneira, na vida cotidiana, nas identidades ou identificações, muda os comportamentos, cria necessidades, e é diretamente ligada às mutações que afetam os modos de vida e seus valores.

A moda induz constantemente a vida em Coletividade, as pessoas são levadas pelo princípio da imitação, o instinto mimético que, segundo Simmel (1988), é uma sólida maneira de integração social. Mas o dilema da moda reside nas dicotomias entre reunir algumas pessoas, e ao mesmo tempo isolar outras, entre fazer e ser como os outros e a vontade de inventar formas de vida originais. Segundo o autor:

Aqui estão as condições relacionadas com a moda enquanto fenômeno difundido por todos os lados na história de nossa espécie. Imitação de um modelo dado, a moda satisfaz uma necessidade de apoio social, ela leva o indivíduo por uma via seguida por todos, ela indica uma generalidade que reduz o comportamento de cada um a um puro e simples exemplo. Dito isto, ela satisfaz tanto a necessidade de distinção, como a tendência à diferenciação, à variedade e à demarcação (Simmel, 1988, p. 92).

A moda permite assim a existência de uma lógica de identificação a partir da imagem ou do personagem para atuar socialmente. É uma ferramenta, um princípio de inserção em um grupo ou tribo. Ela é uma maneira de comunicação, nós podemos transmitir, de acordo com nossas roupas, símbolos que dizem respeito ao nosso trabalho, classe social, idade, país e variados gostos estéticos. Segundo a noção de formismo postulada por Michel Maffesoli (1990), podemos considerar a moda como um dos instrumentos da passagem, da procura da identidade para a procura da identificação. É a forma que fará a identificação, o traje ordena as relações sociais na teatralização do quotidiano. De acordo com Michel Maffesoli:

A criação em questão se aplica sobre todas as obras da cultura, incluindo as mais minúsculas; como a criação quotidiana onde cada instante é eterno. Em tal dinâmica estática, os diversos rituais, os trajes, as paradas, os pequenos e grandes momentos festivos, todos estes 'nadas' que fazem a existência do dia a dia tomam "forma", se ordenam em uma vista arquitetônica que constitui o efêmero e portanto eterno thétrummundi (Maffesoli, 1990, p. 114). 
Nos eventos festivos, os mais variados, como as festas e os shows do mês de junho no Agreste pernambucano, podemos perceber o que prevalece enquanto moda. Ou seja, uma relação diferente com o tempo, uma ruptura com a continuidade e a monotonia, a moda é repetição e retomada. Ela prepara os corpos às diversas representações quotidianas e pode revelar, nas pessoas, o sentimento de compartilhamento. Devemos observar então o que existe na repetição festiva de todos os dias, na vontade de se deixar levar pelas flutuações estéticas.

\section{A moda torna-se o maior fator da festa urbana, e o fator principal da carnavalização do quotidiano. Os diferentes trajes do dia-a-dia tornam-se uma maneira de fazer um carnaval, no sentido que estas mudanças representam uma ruptura com certos códigos estéticos.}

Os diferentes espaços do quotidiano, a rua, o trabalho, ou o transporte público são os lugares comuns da teatralização, então o vestuário toma, de certa maneira, a função de fantasia. A moda torna-se o maior fator da festa urbana, e o fator principal da carnavalização do quotidiano. Os diferentes trajes do dia-a-dia tornam-se uma maneira de fazer um carnaval, no sentido que estas mudanças representam uma ruptura com certos códigos estéticos: o exemplo da mistura de tendências é flagrante, do uso das cores, como o rosa, os diferentes acessórios, os braceletes, os brincos, os colares, são utilizados tanto por homens quanto por mulheres. É como uma deriva no universo consagrado ao prazer, uma jubilação do corpo. Isto origina ações de diversos tipos, elas podem ser individuais ou coletivas, mostradas ou escondidas. Cada elemento do traje, qualquer que seja sua origem e seu caráter próprio, pode contribuir para a passagem do individual para o coletivo.

No seu percurso cíclico, a tendência geral da moda seria,antes de mais nada, a fusão de diferentes estilos e épocas, para se vestir, segundo seus próprios gostos ou identificações. Tal é o exemplo do estilo proposto pelo estilista francês Christian Lacroix, da pesquisa do tempo presente, mesmo com todas as referências poéticas ao passado. Um rito de rotina que assinala uma comunicação entre os viventes. A moda representa igualmente o eterno recomeço, do tempo que segue os diferentes ciclos da natureza, diferenciando cada coleção.

\section{A imitação e seu papel social}

A noção de reminiscência presente nos textos de Platão não seria uma alusão ao que hoje denominamos imitação? Sob a ótica platônica, a busca pela Beleza Absoluta nas produções humanas é uma eterna tentativa (afinal tal beleza seria inatingível no mundo sensível) de imitação, de repetição ou tentativa de repetição de um modelo. Huisman (2000) afirma que, conforme Platão, deveríamos imitar "os gênios mais vetustos" (Huisman, 2000, p. 25). É válida, então, a pergunta: é possível deixar de imitar os nossos semelhantes? Qual é o ser humano que pode escapar ou desvencilhar-se de sua própria essência, da característica gregária? Mesmo o anacoreta assim não nasce, antes de distanciar-se, envolve-se com aqueles que o cercam e os imita, formando uma tribo. Até a desgarrada criança que cresce em meio a outros animais, incorpora-se ao grupo que encontra, repetindo seus comportamentos e gestos. "Não existimos senão no e pelo olhar do outro" (Maffesoli, 2003, p. 129).

\section{A imitação, esse comportamento de repetição de modelos, tem grande relevância para a moda, pois permite uma identificação, através do vestuário, com as tendências internacionais. Fenômeno característico do pólo de confecções do Agreste, a imitação, torna-se um meio de segurança, de sucesso de vendas.}

Como dito anteriormente, Simmel (2008) descreve a moda como "um jogo da incessante imitação de uma classe por outra, como meio de inserção de indivíduos num grupo ou numa corrente" (Simmel, 2008, p. 17). Essa perspectiva a respeito do fenômeno da moda também pode ser encontrada, de modo bastante similar, em Gabriel Tarde, que vê a imitação como uma das atividades fundamentais que constitui o meio social. Portanto, a imitação, esse comportamento de repetição de modelos, tem grande relevância para a moda, pois permite uma identificação, através do vestuário, com as tendências internacionais. Fenômeno característico do pólo de confecções do Agreste, a imitação, torna-se um meio de segurança, de sucesso de vendas. No artigo Pólo de confecções investe e vive grande momento publicado 
no Jornal do Comércio, podemos compreender melhor este procedimento.

Existe um time de empresas no pólo de confecções (em Caruaru, Toritama e Santa Cruz do Capibaribe) que estilistas próprios, equipe de criação e empresários que fazem viagens internacionais antes de lançar as suas coleções. É o caso da Tavernit, Rota do Mar, Iska Viva e da Mamute Confecções, entre outras. 'Geralmente depois do carnaval, vamos ao Havaí e Califórnia, nos Estados Unidos, e visitamos a Tailândia para pesquisar tendências, design e tecidos', comentou o diretor da Rota do Mar, Arnaldo Xavier. Ele acredita que a viagem é um investimento e traz um grande retorno ao negócio (Belfort, 2008, p. 4).

Vale destacar na declaração do diretor da marca Rota do Mar, que a tendência internacional assegura-lhe bons negócios. Também fica salientado, segundo o diretor da marca, que se trata apenas da observação das tendências. Quando algo é declarado inédito ou inovador, no sentido de não ser fruto de qualquer forma de imitação, alguns podem considerar que o ato de imitar uma obra não seria ético. Está por trás disso não somente a vontade de preservar as virtudes e segregá-las a pequenos grupos, mas também o medo do ordinário. Entretanto, esse risco só existe para os que acreditam na criação que parte do nada e defendem o individualismo, a identidade e não a pessoa (persona), ou a identificação. As diversas manifestações da socialidade pós-moderna revelam a força de um tribalismo ligado a uma intuição imitativa.

Com efeito, as leis da imitação, a difusão viral parecem, atualmente, prevalecer, sobre as decisões individualistas, racionalmente elaboradas. Em suma, tudo isso remete para o pensamento como matriz global na qual estamos imersos. Mais somos pensados do que propriamente pensamos (Maffesoli, 1998, p. 169)

A partir dessas proposições teóricas podemos entender a imitação como uma vontade de viver em grupo. Por outro lado, a imitação também possibilita um movimento contrário, quando por oposição, reformação ou combinação, enfim por qualquer forma de desvio, o ato imitativo transforma-se em ato criativo. Sempre há na imitação algo que se altera em intensidades diversificadas. Affonso Romano de Sant' Anna (2003) propõe um modelo que engloba quatro idéias essenciais: paródia, paráfrase, apropriação e estilização; todas elas remetem ao princípio da imitação, à tomada de uma referência externa ao sujeito envolvido com a criação. Apesar de haver uma maior frequência dessas práticas a partir das vanguardas do início do século XX, Sant'Anna considera que elas estão presentes nos mais diversos períodos da história, como na Antiguidade Clássica e na Idade Média. A frase "nada se cria, tudo se copia" é ratificada constantemente pelas práticas sociais.

Se a palavra "invenção" tem um sentido, este é bem o de fazer vir (in-venire) à aquilo que existe, e já está aí. Mas, por pouco que se leve isto a sério, trata-se de uma ambição intelectual que está longe de ser negligenciável (Maffesoli, 1998, p. 129).

Percebe-se no Método Suzuki (Gerling, 1989), um método de ensino de violino para crianças a partir de dois anos de idade, a importância da imitação para a aprendizagem. Schinichi Suzuki observou que ao tomar o modelo do aprendizado da língua pátria, que está baseado na repetição dos modelos fonéticos fornecidos pelos pais, o aprendizado da música torna-se mais natural e promove resultados impressionantes.

A imagem é imitação interiorizada, origina-se do processo de acomodação das pulsões subjetivas aos objetos exteriores. A criação, portanto, é também, seleção e transposição de imagens, construídas no íntimo do sujeito por meio de singulares imitações interiorizadas a partir de modelos externos.

Outra perspectiva similar é dada por MaxBense (2003), que vê a criação como um processo de "transmissão consciente" ou ainda como uma passagem de elementos de uma distribuição para outra. E como nem todos os elementos são transportados nesse processo, os atos criativos são realizados através de seleção. Apesar de Bense(2003) limitar-se a usar exemplos simplistas (como a transposição das cores de uma paleta para uma tela), pode-se relacionar esse pensamento ao repertório imagético do artista. Jean Piaget, por sua vez, encontra em suas observações uma estreita 
relação entre a imitação e a formação dos símbolos. Este último autor afirma que a imitação é base fundadora do sistema simbólico humano, ou seja, o ser humano é capaz de significar porque é capaz de imitar. A imagem é imitação interiorizada, origina-se do processo de acomodação das pulsões subjetivas aos objetos exteriores. A criação, portanto, é também, seleção e transposição de imagens, construídas no íntimo do sujeito por meio de singulares imitações interiorizadas a partir de modelos externos.

É essa conjunção entre a imitação, efetiva ou mental, de um modelo ausente, e as significações fornecidas pelas diversas formas de assimilação que permite a constituição da função simbólica (Piaget, 1978, p. 12).

Esses pontos de vista permitem entender que a imitação tem um papel importante, pois ela é fundamental no processo de aprendizagem, na formação das tribos pós-modernas e na dinâmica da moda. Essas relações ocorrem porque a imitação está intimamente ligada com o imaginário. Na imersão feita no universo da moda de Toritama, encontramos exemplos desse fenômeno. Como descrito por Alves e Callou (no prelo) e também por moradores antigos da cidade, houve uma mudança em Toritama da predominância da produção de calçados à da confecção de jeans no início da década de 1980. Tal mudança, que envolveu a cidade como um todo, evidencia um acreditar e agir em conjunto, que é a base para a existência das tribos e da moda.

\section{Para imitar é preciso imaginar}

A cultura se dinamiza em um processo de estruturação do imaginário por meio de símbolos e o simbólico funciona como articulação do imaginário. Assim, as manifestações culturais são o campo privilegiado para conhecermos a imaginação simbólica de uma sociedade. Segundo Danielle Rocha Pitta (2005) é no imaginário que nós podemos encontrar a identidade mítica de uma cultura. Gilbert Durand define o imaginário como:

O conjunto de imagens e de relações de imagens que constituem o capital pensado do homo sapiens - ele nos aparece como o grande denominador fundamental onde vem se alojar todas os procedimentos do pensamento humano (Rocha Pitta, 2005, p. 15).
A imaginação é a força dinâmica com a qual o homem chega a imaginar o mundo e dar sentido à vida através das imagens. Isso fica evidente nas criações artísticas tão singulares como a moda ou através dos instantes vividos e compartilhados em uma festa popular tão intensa como o São João, na região do Agreste pernambucano. É por meio da imaginação e da concretização das manifestações artísticas que o ser humano chega a dar forma aos aspectos mais efervescentes, mais sensíveis e se "autoafirmar" diante da vida. É uma maneira de transcendência, de contemplação, de força, que edifica e revigora o homem diante das dificuldades da vida. A imitação, por sua vez, é uma exemplificação deste processo da imaginação.

\section{É por meio da imaginação e da concretização das manifestações artísticas que o ser humano chega a dar forma aos aspectos mais efervescentes, mais sensíveis e se "auto afirmar" diante da vida.}

\section{Imitação em Toritama}

Algumas tendências da moda internacional não são extensíveis à produção de localidades como Toritama. Mesmo estando relacionados com as tendências mundiais, existem particulares locais que inviabilizam algumas propostas, eis que estamos tratando de um imaginário particular. Não é simplesmente porque algo faz sucesso nas capitais européias ou nas capitais do Sudeste do Brasil, que será adotado pela confecções do nordeste brasileiro. Além das noções limitantes sobre globalização, existe o "saber popular". Um exemplo disso está no estilo boyfriend para calças femininas que não foi incorporado por boa parte das coleções de Toritama.

O estilo boyfriend refere-se a uma modelagem de calças jeans feminina mais folgada, que não acompanha as linhas do corpo. A palavra inglesa que nomeia o estilo faz alusão à condição da mulher que usa, ou parece usar, as calças do namorado. Um dos principais fatores que provavelmente contribuiupara a não aceitação na região do estilo boyfriend é o culto ao corpo ligado à carnavalização no quotidiano, perceptível nas calças de Toritama. Para os produtores e consumidores de Toritama, há o sentimento do prazer orgiático, ou seja, do compartilhamento de emoções que está diretamente relacionado à sensualidade. 
Esta é pedida nas folgadas calças boyfriend, já que escondem as curvas do corpo feminino. Os cortes justos e decotados, os tingimentos e os adereços utilizados pelas empresas de confecção em Toritama, evocam os prazeres da existência.

Toritama enquanto grande centro comercial deve seu sucesso à comunhão que as pessoas fazem em torno da produção de jeans. Comunhão que é compartilhar, tornar comum a vida. Nesse contexto, a imitação toma uma posição de destaque, é vetor de religação, que possibilita a vibração em conjunto. A sociedade transpira uma imitação velada, comum e subterrânea, posto que não é admitida publicamente. Identifica-se facilmente que há inúmeras repetições entre as produções do vestuário em jeans de Toritama - algo esperado e reconhecido no campo da moda como descrito por Simmel -, presentes desde a escolha dos botões até a modelagem das peças.

O modo como a produção em Toritama ocorre, demonstra o imaginário dessa população. Diferente da maioria dos lugares do mundo, onde a moda trabalha com quatro coleções por ano, as empresas de Toritama produzem doze, vinte e quatro ou até mais coleções por ano.

Como um dos principais exemplos da imitação presente nas confecções de Toritama, encontramos o uso dos "cadernos de tendências". Estes cadernos trazem uma série de soluções possíveis, apresentadas de forma detalhada, que agregam tendências da moda nacional e internacional. A partir da inserção desses cadernos, ocorre um movimento de imitação criativa, no sentido em que são feitos desvios intencionais na repetição dos modelos propostos. É um processo similar ao descrito por Louro (1996/97), quando esta autora trata da aplicação do Método Suzuki. Apesar de existirem críticas em relação à massificação provocada por essa prática, a autora considera que não há um bloqueio da criação, antes disso a repetição consistente fornece uma base firme para o exercício da criatividade.

O conceito ocidental de que a variedade é interessante e a repetição monótona é o oposto do oriental onde a repetição não é vista como sendo enfadonha (Gerling, 1989, p. 55).

Encontramos em Toritama um universo que transcende à ditadura da variação, que não con- corda com a pregação de que a inovação seria a grande salvadora do mundo "subdesenvolvido". A imitação aparece em Toritama como em uma comunidade de artesãos, na qual não há a preocupação excessivaem relação ao plágio, posto que os desvios são constantes. A repetição de modelos nessa cidade, é, antes de tudo, definidora de uma estética local, de uma tradição produtiva comungada, visto que toda a cidade está inserida no contexto da produção de jeans. Encontra-se em Toritama desde carregadores, que levam pelas ruas as peças de roupa nos ombros, até enormes placas que divulgam as marcas e empresas da cidade que são responsáveis pela produção de jeans. A identidade visual da prefeitura, por sua vez, apresenta uma calça jeans, além de trazer o slogan "a capital do jeans", exemplificando a intensidade do envolvimento de toda a cidade nas "dobras" da moda.

\section{REFERÊNCIAS}

ALVES, Rosiane Pereira; CALLOU, Ângelo Brás Fernandes. Moda e desenvolvimento social: reconversões culturais na criação e confecção do jeans. Viçosa: Oikos, no prelo.

BAYER, R. História da Estética. Lisboa, Editorial Estampa, 1995.

BELFORT, Ângela Fernanda. Jornal do Comércio, Caderno de Economia, Recife, $1^{\circ}$ de junho de 2008, p. 4.

BENSE, Max. Criatividade relativa. In: Pequena estética. 3. ed. São Paulo: Editora Perspectiva, 2003. p. 91-95.

DURAND, Gilbert. Les structures anthropologiques de l'imaginaire. Paris: Bordas, 1969.

GERLING, Fredi. Suzuki: o método e o mito. In: Em Pauta, Porto Alegre, v. 1, n. 1, p. 47-56, 1989.

HUISMAN, Denis. A estética. Lisboa: Edições 70, 2000.

LOURO, Ana Lucia de Marques e. Método Suzuki: repertorio e imitação criativa. In: Em Pauta, Porto Alegre, v. 8/9, n. $12 / 13$, p. $79-88,1996 / 97$.

MAFFESOLI, Michel. O instante eterno: o retorno do trágico nas sociedades pós-modernas. São Paulo: Ed. Zouk, 2003.

Elogio da razão sensível. Petrópolis: Ed. Vozes, 1998.

. Au creux des apparences. Ed. Plon, 1990.

PIAGET, Jean. A formação do símbolo na criança: imitação, jogo e sonho, imagem e representação. 3. ed. Rio de Janeiro: J. Zahar, 1978.

ROCHA PITTA, Danielle. Iniciação à teoria do imaginário de Gilbert Durand. Rio de Janeiro: Atlantica Editora, 2005.

SANT'ANNA, Affonso Romano de. Paródia, parágrafos E cia. 7. ed. São Paulo: Ática, 2003.

SIMMEL, Georg. Filosofia da moda e outros escritos. Lisboa: Edições texto e gráfica, 2008. . La tragédie de La culture. Paris: Ed. Rivages, 1988. 